\title{
To Evaluate Corneal Biomechanical Changes after Strabismus Surgery with Ocular Response Analyzer
}

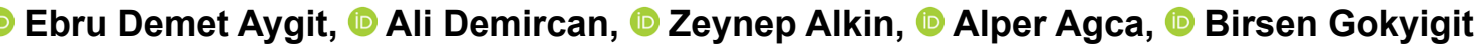 \\ University of Health Sciences, Beyoglu Eye Training and Research Hospital, Istanbul, Turkey
}

\begin{abstract}
Objectives: Corneal biomechanical changes were also suspected and investigated after some scleral procedures but not after strabismus surgery. In this study, we aimed to evaluate corneal biomechanical changes following strabismus procedures with ocular response analyzer.

Methods: This study was a retrospective case series. Corneal biomechanical properties were assessed using the ocular response analyzer (ORA) (ORA, Reichert Inc., Depew, New York, USA) before and 6 months after the surgery in 67 eyes of 67 patients performing strabismus surgery. Pre- and post-operative changes in corneal hysteresis $(\mathrm{CH})$ and corneal resistance factor (CRF) outcomes were examined.

Results: The study group were divided into Groups I and 2 for the performed surgery. Pre- and post-operative CRFs were showed statistically significant differences in Groups I and 2. In Group I, the mean CH was II.7 $\pm 2.4 \mathrm{mmHg}$ at preoperative and $12.3 \pm 2.5 \mathrm{mmHg}$ at postoperative. The differences were not statistically significant in Group I.

Conclusion: This is the first study aimed to evaluate the corneal biomechanical changes after strabismus surgery. and CRF were found to statistically significance at 6 month after strabismus surgery.

Keywords: Corneal biomechanics, ocular response analyzer, strabismus surgery.
\end{abstract}

\section{Introduction}

Ocular misalignment among adults differs significantly from pediatric strabismus, a well-characterized disorder, in which esotropia, exotropia, and hypertropia occur with similar frequency ( 1 ). The prevalence of strabismus ranges from about $3 \%$ to $5 \%(2-4)$. Its etiology is complex, being influenced by heredity and environmental factors. Chen et al. studied preschool children in Eastern China and found $5.65 \%$ strabismus prevalence $(5,6)$.

The ocular response analyzer (ORA) (Reichert Ophthalmic Instruments, Buffalo, USA) has been used to compensate for the corneal effects on IOP measurements by providing new measurements of corneal tissue properties. For many years, the ORA measures corneal hysteresis $(\mathrm{CH})$, which is a measure of the viscous dampening properties of the cornea and the corneal resistance factor (CRF). The CRF is the measure of the overall resistance of the cornea (7).

The impact on $\mathrm{CH}$ and $\mathrm{CRF}$ of treatment-related structural changes of the cornea, those changes occurring after refractive surgical procedures, placement of intracorneal rings, and collagen crosslinking as well as the pathological changes of the cornea (e.g., those resulting from keratoconus, edema, and glaucoma) has also been discussed $(8,9)$.

Astigmatic changes after routine strabismus surgery have been reported and most of the studies shown that these changes were non-significant and persistent (10). These changes indicate a change in corneal shape. Corneal biomechanical changes were also suspected and investigated after some scleral procedures but not after strabismus surgery. Strabismus surgery is performed on the sclera, and changes

Address for correspondence: Ebru Demet Aygit, MD. Beyoglu Goz Egitim ve Arastirma Hastanesi, Saglik Bilimleri Universitesi, Istanbul, Turkey

Phone: +90 2122515900 E-mail: ebrudemet@hotmail.com

Submitted Date: June 05, 2018 Accepted Date: August 14, 2018 Available Online Date: December 19, 2018

${ }^{\circ}$ Copyright 2018 by Beyoglu Eye Training and Research Hospital - Available online at www.beyoglueye.com 
of scleral rigidity may affect corneal biomechanical changes. In this study, we aimed to evaluate the changes in corneal biomechanical properties following strabismus surgery.

\section{Methods}

This retrospective, observative study reviewed the records of the patients who underwent strabismus surgery between April 2013 and January 2014 and consecutive patients were selected; during this period, the study adhered to the tenets of the Declaration of Helsinki, and the study protocol was approved by the Hospital's Institutional Review Board.

To be included in the study, each patient was required to meet all of the following criteria: Age between 5 and 18 years and minimum follow-up time of 6 months. Patients were not included in the study if they were contact lens wearers, had previous intraocular or extraocular surgery, had any corneal disease such as keratoconus, or had corneal dystrophies or corneal scars. Only the patients who underwent uneventful horizontal muscle recession or resection of one extraocular muscle were included in the study. Patients were classified as Group I (recession) or Group 2 (resection).

Data collected from the patients' records included age, gender, visual acuity, and cycloplegic refraction.

Information on the affected eye and the findings from the performed surgery were recorded at the baseline, and an evaluation of the corneal biomechanical properties using the ORA was performed and recorded at baseline and month 6. The ORA was used to measure $\mathrm{CH}$ and the CRF with the use of a patented applanation two-way dynamic system (7).

All patients underwent a standardized examination in which a measurement of visual acuity was determined using a Snellen chart with a "tumbling E" and expressed with its decimal equivalent. Cycloplegic refraction was carried out in all eyes, either with an Auto Refractometer (KR-8800) or a handheld autorefractor (Retinomax K-Plus 3). Cyclo- plegic spherical equivalent refraction values were used for statistical analysis in all cases. Finally, a biomicroscopy and biomicroscopic fundus examination was performed.

\section{Surgical Technique}

All procedures were performed between April 2013 and January 2014 by two surgeons at the same center (BG, EDA). Conjunctival limbal incision was made related muscle area. After the muscle is hooked and muscle was cleared of adherent tissues. A resection or recession procedure was performed.

\section{Statistical Data Analysis}

The data analysis was carried out with the SPSS software version 15.0 (SPSS, Inc., Chicago, IL, USA). The data were classified as mean \pm standard deviation. For analyzing the age, sex descriptive statistics was utilized. For comparison in the pre- and post-surgery values, the Wilcoxon signed-ranks test was applied. $\mathrm{P}<0.05$ was considered to be statistically significant.

\section{Results}

A total of 67 eyes from 67 patients were included in this study. 34 (50.7\%) were from male subjects and 33 (49.3\%) from female subjects. The mean age of the subjects was $13.3 \pm 4.8$ years (range $5-18$ years). 34 (50.7\%) of the eyes were right and $33(49.3 \%)$ eyes were left. The follow-up period was a minimum of 6 months.

35 (52.2\%) patients (mean age: II.3) performed recession (Group I) and the other 32 (47.8\%) patients (mean age: I5.2) performed resection (Group 2) horizontal strabismus surgery. Our patients' mean axial length was found to be $23.2 \pm 1.8 \mathrm{~mm}$. ORA parameters of pre- and post-operative are shown in Tables I and 2. Pre- and post-operative CRFs were showed statistically significant differences in Groups I and 2.

Table I. Pre- and post-operative ORA parameters

\begin{tabular}{|c|c|c|c|c|}
\hline \multirow[t]{3}{*}{ ORA parameters } & \multicolumn{2}{|c|}{ Group I $(n=35)$} & \multicolumn{2}{|c|}{ Group 2 (n=32) } \\
\hline & $\mathrm{CH}$ & CRF & $\mathbf{C H}$ & CRF \\
\hline & Min-max & Min-max & Min-max & Min-max \\
\hline Pre-operative $(\mathrm{mmHg})$ & $7-16.8$ & $7.2-16$ & $4.9-15.2$ & $3.6-14$ \\
\hline & $(12.3 \pm 2.5)$ & $(12.4 \pm 2.4)$ & $(12.1 \pm 2)$ & $(12 \pm 2.2)$ \\
\hline$P$ & 0.07 & 0.023 & 0.009 & 0.001 \\
\hline
\end{tabular}

$\mathrm{CH}$ : Corneal hysteresis; CRF: Corneal resistance factor; min: Minimum; max: Maximum; ORA: Ocular response analyzer. 
Table 2. Pre- and post-operative ORA parameters

\begin{tabular}{|c|c|c|c|c|}
\hline \multirow[t]{3}{*}{ ORA parameters } & \multicolumn{2}{|c|}{ Group I $(n=35)$} & \multicolumn{2}{|c|}{ Group $2(n=32)$} \\
\hline & $\mathrm{CH}$ & CRF & $\mathrm{CH}$ & CRF \\
\hline & Mean士SD & Mean士SD & Mean士SD & Mean \pm SD \\
\hline Pre-operative (mmHg) & $11.7 \pm 2.4$ & $11.5 \pm 2.3$ & $10.8 \pm 2.9$ & $10.4 \pm 2.7$ \\
\hline Post-operative (mmHg) & $12.3 \pm 2.5$ & $12.4 \pm 2.4$ & $12.1 \pm 2$ & $12 \pm 2.2$ \\
\hline $\mathrm{p}$ & 0.07 & 0.023 & 0.009 & 0.001 \\
\hline
\end{tabular}

$\mathrm{CH}$ : Corneal hysteresis; CRF: Corneal resistance factor; ORA: Ocular response analyzer.

\section{Discussion}

Hysteresis $(\mathrm{CH})$, a parameter that characterizes the biomechanical condition of the cornea, is the result of the ocular resistance caused by the combined effects of corneal thickness, ocular rigidity, and its biomechanical properties. CRF is considered a good indicator of the cornea's total viscoelastic response and an indicator of the overall "resistance" of the cornea (9).

Corneal refractive surgery is the most frequently surgery which is investigated by corneal biomechanical effects. Changes in corneal tissue after refractive surgery have been reported in the literature $(10-13)$. Many studies were reported stating reduced IOP readings after corneal refractive surgery. It is believed, as an indirect evidence of a change in biomechanical properties in the cornea, decreased to IOP after refractive surgery (measured IOP rather than true IOP) (I4-16).

Shah et al. study (12) addressed the differences in biomechanical properties in hyperopic eyes compared to myopic eyes following refractive surgery. They found that $\mathrm{CH}$ and CRF were found to decrease after both myopic and hyperopic refractive surgeries. A study of Chen et al. (II) assessed the correlation between corneal biomechanical properties and surgical parameters in myopic patients before and after laser in situ keratomileusis (LASIK). They revealed that changes in $\mathrm{CH}$ and CRF after LASIK suggest alteration in corneal biomechanics correlating with attempted correction. The CRF parameter may be more useful than the $\mathrm{CH}$ parameter in assessing biomechanical changes resulting from LASIK (II).

Strabismus surgery is performed mainly on ocular muscles and scleral tissues. Sclera is histologically closely related to corneal tissue, and together with cornea, they form a closed system. Thus, corneal biomechanical changes may occur after scleral procedures. Strabismus surgery is performed adjacent to the cornea and can possibly lead to changes in the viscoelastic properties of the cornea. Some biomechanical changes have been reported after scleral procedures, but such a relationship has not been investigated for strabismus surgery before (17). Two studies have investigated the effects of scleral procedures on corneal biome- chanical properties before Seymenoğlu et al. (18) who evaluated 23-gauge transconjunctival sutureless vitrectomy (23-G TSV) and Ruiz-De-Gopegui et al. (19) who investigated the effects of encircling scleral buckle (SB).

Seymenoglu et al. (18) reported that, in surgeries using 23-gauge transconjunctival sutureless vitrectomy (23-G TSV), there is a significant difference in mean $\mathrm{CH}$ between pre-operative and I-month post-operative measurements. 3 months after the surgery, they found that there were no statistically significant differences compared to pre-operative values.

The length of the ocular circumference is shortened in the area of the buckle implant, and the volume of the vitreous cavity diminished after scleral buckle (20-22). DeGopegui et al. (19) investigated the effects of encircling SB on the corneal biomechanical properties of the cornea and their morphological parameters. This study showed to mean $\mathrm{CH}$ diminished significantly from $10.2 \pm 1.7 \mathrm{mmHg}$ to $7.6 \pm 1.1 \mathrm{mmHg}$ after PPV/SC ( $p=0.003$, Wilcoxon test) but not after the independent PPV $(9.8 \pm 3.2 \mathrm{mmHg}$ vs. I I.6 \pm 2.7 $\mathrm{mmHg}, \mathrm{p}=0.465$, Wilcoxon test). The CRF did not change significantly after surgery in any of the groups/the corneal morphology parameters measured before and after surgery in both groups. Neither the PPV/SC group nor the independent PPV group exhibited significant changes in these parameters after surgery $(p>0.05)$.

In our study, we found statistically significance between pre- and post-operative CRFs in two groups. CRF is a measurement of corneal resistance that is relatively independent of IOP, and our study shows that CRF could have affected the scleral changes. This result was similar and it was supported by Chen et al. study.

Our study supports these previous studies and the view that scleral procedures may have an effect on corneal biomechanical structure. When strabismus surgery is considered, muscle tension changes on sclera may be the major reason of corneal changes and it has been shown that strabismus surgery results in a mild but persistent change in corneal astigmatism (17). Other effects of strabismus surgery such as segmental changes in the ciliary body circulation and the wound healing in the area of the scleral adhesion of extraoc- 
ular muscles may also affect the globe rigidity (20-22).

Limitations of our study were the short follow-up time and the wide age range.

\section{Conclusion}

This is the first study aimed to assess the corneal biomechanical changes after strabismus surgery. It supports the view that surgeries performed on ocular structures in very close proximity to cornea may also have an effect on $\mathrm{CH}$ and CRF measurements. This effect may not be considered clinically significant in most of the cases. However, $\mathrm{CH}$ and CRF are evaluated to investigate a variety of corneal pathologies and procedures. Thus, the presence of such a relationship may have an impact on evaluating results of $\mathrm{CH}$ and CRF in such cases. Studies with large sample size should be performed to confirm our findings.

\section{Disclosures}

Acknowledgments: This study was conducted in accordance with the Institutional Review Board regulations and with the principles of the Declaration of Helsinki.

Informed consent was obtained from all individual participants included in the study.

Peer-review: Externally peer-reviewed.

Conflict of Interest: None declared.

Authorship Contributions: Involved in design and conduct of the study (EDA, AD, ZTA); preparation and review of the study (EDA, AA, BG); data collection (EDA, AD); and statistical analysis (EDA, AD, ZTA).

\section{References}

I. Martinez-Thompson JM, Diehl NN, Holmes JM, Mohney BG. Incidence, types, and lifetime risk of adult-onset strabismus. Ophthalmology 2014;121:877-82.

2. Graham PA. Epidemiology of strabismus. $\mathrm{Br} \mathrm{J}$ Ophthamol 1974:58;224-31.

3. Preslan MW, Novak A. Baltimore Vision Screening Project. Ophthalmology 1996;103:105-9.

4. Abrahamsson M, Magnusson G, Sjöstrand J. Inheritance of strabismus and the gain of using heredity to determine populations at risk of developing strabismus. Acta Ophthalmol Scand 1999;77:653-7.

5. Chen X, Fu Z, Yu J, Ding H, Bai J, Chen J, et al. Prevalence of amblyopia and strabismus in Eastern China: results from screening of preschool children aged 36-72 months. Br J Ophthalmol 2016;100:515-9.

6. Wan MJ, Hunter DG. Complications of strabismus surgery: incidence and risk factors. Semin Ophthalmol 2014;29:42I-8.

7. Luce DA. Determining in vivo biomechanical properties of the cornea with an ocular response analyzer. J Cataract Refract Surg 2005;31:156-62.

8. Beyazyıldız E, Beyazyıldız O, Arifoğlu HB, Altıntaş AK, Köklü
SG. Comparison of ocular response analyzer parameters in primary open angle glaucoma and exfoliative glaucoma patients. Indian J Ophthalmol 2014;62:782-7.

9. Terai N, Raiskup F, Haustein M, Pillunat LE, Spoerl E. Identification of biomechanical properties of the cornea: the ocular response analyzer. Curr Eye Res 2012;37:553-62.

10. Pepose JS, Feigenbaum SK, Qazi MA, Sanderson JP, Roberts CJ. Changes in corneal biomechanics and intraocular pressure following LASIK using static, dynamic, and noncontact tonometry. Am J Ophthalmol 2007; |43:39-47.

I I. Chen MC, Lee N, Bourla N, Hamilton DR. Corneal biomechanical measurements before and after laser in situ keratomileusis. J Cataract Refract Surg 2008;34:I886-9I.

12. Shah S, Laiquzzaman M, Yeung I, Pan X, Roberts C. The use of the ocular response analyser to determine corneal hysteresis in eyes before and after excimer laser refractive surgery. Cont Lens Anterior Eye 2009;32:123-8.

I3. Emara B, Probst LE, Tingey DP, Kennedy DW, Willms LJ, Machat J. Correlation of intraocular pressure and central corneal thickness in normal myopic eyes and after laser in situ keratomileusis. J Cataract Refract Surg 1998;24:1320-5.

14. Levy Y, Zadok D, Glovinsky Y, Krakowski D, Nemet P. Tono-Pen versus Goldmann tonometry after excimer laser photorefractive keratectomy. J Cataract Refract Surg 1999;25:486-91.

15. Zadok D, Tran DB, Twa M, Carpenter M, Schanzlin DJ. Pneumotonometry versus Goldmann tonometry after laser in situ keratomileusis for myopia. J Cataract Refract Surg 1999;25: 1344-8.

16. Munger R, Dohadwala AA, Hodge WG, Jackson WB, Mintsioulis G, Damji KF. Changes in measured intraocular pressure after hyperopic photorefractive keratectomy. J Cataract Refract Surg 200।;27:1254-62.

I7. Snir M, Nissenkorn I, Buckman G, Cohen S, Ben-Sira I. Postoperative refractive changes in children with congenital esotropia: a preliminary study. Ophthalmic Surg 1989;20:57-62

18. Seymenoğlu G, Uzun Ö, Başer E. Surgically induced changes in corneal viscoelastic properties after 23-gauge pars plana vitrectomy using ocular response analyzer. Curr Eye Res 2013;38:3540.

19. Ruiz-De-Gopegui E, Ascaso FJ, Del Buey MA, Cristóbal JA. Effects of encircling scleral buckling on the morphology and biomechanical properties of the cornea [Article in Spanish]. Arch Soc Esp Oftalmol 2011;86:363-7.

20. Johnson MW, Han DP, Hoffman KE. The effect of scleral buckling on ocular rigidity. Ophthalmology 1990;97:190-5.

2I. Teke MY, Elgin U, Sen E, Ozdal P, Ozturk F. Intravitreal silicone oil induced changes in corneal biomechanics. Int Ophthalmol 20। 4;34:457-63.

22. Shi MG, Qiao BD, Zhou YX. The volume and dimensions of eyeball analyzed by MRI following encircling scleral buckles [Article in Chinese]. Zhonghua Yan Ke Za Zhi 2006;42:150-4. 